\title{
Lei dos Crimes Hediondos - LHC
}

\section{Matheus Lima Marques}

Estudante de Direito da

Faculdade 7 de Setembro 



\section{Lei dos Crimes Hediondos - LHC}

\section{CO INTRODUÇÃO}

Há quatorze anos em vigência, a Lei 8.072/90 (Lei dos Crimes HediondosLCH) proporcionou várias mudanças no campo do Direito Penal brasileiro a partir daí tornou-se alvo de várias críticas.

A doutrina e a jurisprudência divergem ao analisar a Lei dos Crimes Hediondos de forma veemente, uns se posicionam a favor da constitucionalidade da lei e da manutenção desta sem alterações, fundamentando que sem ela daremos um salto para o crescimento da impunidade, que já nos rodeia. Outros defendem a sua inconstitucionalidade por ferir vários princípios fundamentais ao Estado Democrático de Direito. Em nenhum momento a doutrina e a jurisprudência poderão provar que sanções penais mais severas diminuíram a criminalidade.

Numa primeira parte, pretendemos mostrar os pontos polêmicos da lei 8.072/90, fazendo citações de autores e por fim o posicionamento da jurisprudência majoritária. Nesta parte, tratamos sobre a constitucionalidade da lei, a proibição de progressão de regime prisional aos condenados nas penas tipificadas na Lei de Crimes Hediondos; a concessão de liberdade provisória e fiança; a concessão de livramento condicional e a retroatividade da lei penal mais benéfica ao réu.

Numa segunda parte, definiremos um ponto de vista, fundamentado em posições doutrinárias e jurisprudências, embora, saibamos da complexidade do assunto em análise, neste trabalho, todavia procuramos na medida de nossos conhecimentos acadêmicos uma conclusão concisa e fundamentada no posicionamento doutrinário e jurisprudencial que nos familiarizamos. 


\title{
CO LEI 8.072/90, DE 25 DE JULHO DE 1990 (LEI dOS CRIMES HEDIONDOS)
}

\subsection{Momento HistóRico}

Neste tópico, procuraremos abordar se o estado de medo e a insegurança influenciaram diretamente, tanto, ao legislador constituinte na elaboração da Constituição federal de 1988, como, ao legislador ordinário criador da Lei 8.702/90, conflitando as opiniões de autores renomados e a jurisprudência.

Por meio de uma onda de extorsões e seqüestros que atingia os grandes centros urbanos, principalmente na cidade do Rio de Janeiro, é que começou a ser discutido um projeto que tivesse a finalidade amenizar ou acabar com aquelas modalidades delituosas. A manipulação desse fenômeno criminal pelos meios de comunicação gerou um terreno propício para a aprovação de medidas penais mais severas que, visam extinguir da população o medo e a insegurança, criados após episódios famosos, como o seqüestro do empresário carioca Roberto Medina. Alberto Silva Franco, com autoridade de quem escreveu excelente obra sobre a matéria, fato esse que, superdimensionado pelos meios de comunicação, acabou atuando "como um mecanismo de pressão ao qual o legislador não soube resistir" (Crimes Hediondos, 3. ed., São Paulo, RT) ${ }^{1}$. Então, em 1988 com a promulgação da Constituição Federal, que trouxe em seu Título II (DOS DIREITOS E GARANTIAS FUNDAMENTAIS), Capítulo I (DOS DIREITOS E DEVERES INDIVIDUAIS E COLETIVOS), Artigo 5 ${ }^{\circ}$, Inciso XLIII, o seguinte:

\begin{abstract}
"A lei considerará crimes inafiançáveis e insuscetíveis de graça ou anistia a prática da tortura, o tráfico ilícito de entorpecentes e drogas afins, o terrorismo, e os definidos como crimes hediondos, por eles respondendo os mandantes, os executores e os que, podendo evitá-los, se omitirem".
\end{abstract}

\footnotetext{
${ }^{1}$ João José Leal, Lei dos Crimes Hediondos ou Direito Penal da Severidade, Revista Brasileira de Ciências .Criminais-40, 2002, p.160.
} 
Com isso, o legislador constituinte originário, atribuiu competência ao legislador ordinário para legislar respeitando o texto constitucional, este “conhece limitações constitucionais expressas e implícitas e é passível de controle de constitucionalidade" 2 .

Em decorrência da indefinição dos crimes tipificados, no inciso XLIII, e com a necessidade urgente de tipificar atos delituosos cometidos constantemente à época da criação da Lei 8.072/90, a qual, era tida pela a maioria da sociedade como a solução para acabar com aquele estado de medo que enfrentavam. Talvez, devido à falta de discussões mais aprofundadas e o afã da sociedade exigindo punições exacerbadas aos delitos que chocava a sociedade brasileira, por meio do sensacionalismo dos meios de comunicação.

A nenhuma lei de tamanha abrangência como esta não é viável sua publicação atropelando os princípios fundamentais ao Estado que tem o dever de propiciar à sociedade justiça real, ou seja, propiciar justiça por meio leis justas.

Não ocorre nesta lei, o Juízo ou Tribunal de Exceção, previsto no art.5², XXXVII, da Constituição Federal, pois a lei não retroagirá aos crimes que segundo os críticos influenciaram diretamente à publicação da Lei 8.072/90, posteriormente, a Lei 8.930/94 incluindo naquela os crimes tipificados no art. $1^{\circ}$, I "homicídio (art.121), quando praticado em atividade típica de grupo de extermínio, ainda que cometido por um só agente, e homicídio qualificado (art. 121, §2 , I , II , III , IV e V)”. A Lei 8.930/94 foi promulgada, logo após, o homicídio qualificado cometido contra a atriz global Daniela Peres, o que provocou um sensacionalismo enorme ao caso.

Não é raro o princípio da legalidade ser fundamental na maioria dos ordenamentos jurídicos, que a competência é do legislador para criar normas jurídicas, todavia em alguns momentos não seja possível prever todas as condutas humanas capazes de causar problema a sociedade.

Portanto, é correto falar que a Lei 8.072/90, seja uma “Lei de Ocasião”, como diz o autor João José Leal (Revista Brasileira de Ciências Criminais -40, 2002, p. 164). Já que, a política criminal nesta época era favorável a criação de leis mais severas objetivando de forma indireta a satisfação da comunidade com o poder político governante.

${ }^{2}$ Alexandre de Moraes, Direito Constitucional, $13^{\mathrm{a}}$ ed., Atlas, São Paulo, 2003, p. 56. 


\subsection{A Lei 8.072/90 E os Princípios Fundamentais do Estado}

Analisamos até o presente momento, à parte que trata somente se a lei sofreu influência direta do pânico da população, à época de sua publicação. Passamos, neste tópico, a analisar quais os princípios violados e os efeitos decorrentes da violação destes princípios.

Ao falarmos sobre princípios se faz necessário uma abordagem prévia da forma de Estado adotado por nossa Constituição Federal de 1988 e os princípios fundamentais do Estado brasileiro.

A forma de Estado adotada por nossa Constituição, é a prevista em seu art. $1^{\circ}$ :

“A República Federativa do Brasil, formada pela união indissolúvel dos Estados e Municípios e do Distrito Federal, constitui-se em Estado Democrático de Direito e tem como fundamentos: I. a soberania; II. a cidadania; III. a dignidade da pessoa humana; IV. os valores sociais do trabalho e da livre iniciativa; V. o pluralismo político.§ único. Todo o poder emana do povo, que o exerce por meio de representantes eleitos ou diretamente, nos termos desta Constituição”.

José Afonso da Silva define os fundamentos do Estado brasileiro, de acordo com o (art. $1^{\circ}$ da CF/88) a soberania, a cidadania, a dignidade da pessoa humana, os valores sociais do trabalho e da livre iniciativa e o pluralismo político.

A soberania não precisava ser mencionada, porque é fundamento do próprio, conceito de Estado. Constitui também princípio da ordem econômica (art.170). Soberania significa poder político supremo e independente, como observa Marcelo Caetano: supremo, porque “não está limitado por nenhum outro na ordem interna”, independente, porque, "na ordem internacional, não tem de acatar regras que não sejam voluntariamente aceitas e está em pé de igualdade com os poderes supremos dos outros povos”. 
A cidadania está aqui num sentido mais amplo do que o de titular de direitos políticos. Qualifica os participantes da vida do Estado, o reconhecimento do indivíduo como pessoa integrada na sociedade estatal (art. 5, LXXVII). Significa aí, também, que o funcionamento do Estado estará submetido à vontade popular. E aí o termo conexiona-se com o conceito de soberania popular (§único, art. $1^{\circ}$ ), com os direitos políticos (art. 14) e com o conceito da dignidade da pessoa humana (art. $1^{\circ}$, III), com os objetivos da educação (art. 205), como base e meta essencial do regime democrático.

Dignidade da pessoa humana é um valor supremo que atrai o conteúdo de todos os direitos fundamentais do homem, desde o direito a vida:

"Concebido como referência constitucional unificadora de todos os direitos fundamentais [observam Gomes Canotilho e Vital Moreira], o conceito de dignidade da pessoa humana obriga a uma densificação valorativa que tenha por conta seu amplo sentido normativo-constitu-cional e não uma qualquer idéia apriorística do homem, não podendo reduzirse o sentido da dignidade humana à defesa dos direitos pessoais tradicionais, esquecendo-a nos casos de direitos sociais, ou invocá-la para construir 'teoria do núcleo personalidade' individual, ignorando-a quando se trate de garantir as bases da exis-tência humana. Daí decorre que a ordem econô-mica há de ter por fim assegurar a todos a existência digna (art. 170), a ordem social visará a realização da justiça social (art.193), a educação, o desenvolvimento da pessoa e seu preparo para o exercício da cidadania (art. 205) etc., não como meros enunciados formais, mas como indicadores do conteúdo normativo eficaz da dignidade da pessoa humana" ${ }^{3}$.

${ }^{3}$ José Afonso da Silva, Curso de Direito Constitucional Positivo,18 ed., Malheiros, São Paulo, 2000, pp. 108 e 109. 
Como já explicamos acima foi o próprio legislador constituinte, que expressamente atribuiu a lei ordinária à função de definir os crimes hediondos. Alei 8.072/90, em seu art. $1^{\circ}$ os define de forma lacunosa, pois, num primeiro instante deixou de incluir o homicídio doloso, principalmente o qualificado, no rol dos crimes hediondos o que podemos dizer que é uma omissão injustificável, pela as conseqüências que este traz a sociedade. Enquanto, previa no inciso VII-A o crime de envenenamento de água potável ou substância alimentícia ou medicinal qualificado pela morte (art. 270 c/c art. 285), o qual foi excluído da relação dos crimes hediondos pela lei 8.930/94, que entendeu ser desproporcional a tipificação deste delito, naquela lei.

O princípio da proporcionalidade, atualmente, deve ser aplicado ao inciso VII-B (art. $1^{\circ}$ ) para impedir sua eficácia, pois este versa sobre a "falsificação, corrupção, adulteração ou alteração de produto destinado a fins terapêuticos ou medicinais (art. 273 , caput e $\S 1^{\circ}, \S 1^{\circ}-\mathrm{A}$ e $\S 1^{\circ}-\mathrm{B}$, com redação dada pela Lei ${ }^{\circ} 9.677$, de julho de 1998). O art. 273 do Código Penal, diz que:

"Falsificar, corromper, adulterar ou alterar produto destinado a fins terapêuticos ou medicinais: pena-reclusão, de 10 (dez) a (quinze) anos, e multa. A polêmica está aqui, $\$ 1^{\circ}-A$ "incluem-se entre os produtos a que se refere este artigo os medicamentos, as matérias-primas, os insumos farmacêuticos, os cosméticos, os saneantes e os de uso em diagnóstico".

Comentando o artigo, Celso Delmanto leciona que:

“A equiparação de produtos imposta por força deste $\$ 1^{\circ}-A$, incluem-se entre os produtos referidos neste art. 273 os medicamentos (substâncias ou preparados que se utilizam como remédios), as matérias-primas, os insumos farmacêuticos, os cosméticos, os saneantes e os de uso em diagnóstico. De forma absurda, este $\$ 1^{\circ}-A$ inclui entre os produtos objeto deste artigo, punidos com severíssimas penas, os cosméticos (destinados ao embelezamento) e os saneantes (destinados à higienização e à desinfetação ambiental), ferindo, assim, 
o princípio da proporcionalidade. No mesmo sentido, Alberto Silva Franco, "Há produto novo na praça”, in Bol. IBCCr 70/5 - edição especial”" .

E Luiz Régis Prado complementa o raciocínio:

“O princípio da proporcionalidade (proibição de excesso), nele as penas devem sempre guardar razoável proporção com o delito perpetrado e com a forma de sua execução. Inclui-se, aqui, tanto a atividade legislativa, repelindo-se 'como undue process of law, a lei caprichosa, arbitrária no diferenciar tratamento jurídico dado a uma classe de indivíduos' (Francisco Clementino de San Tiago Dantas, Problemas de direito Positivo - Estudos e Pareceres, Forense, 1953, pp. 46-7), quanto à judiciária, ao aplicá-las e executa-las (CR/88, art. 5, caput e LIV; CP. Art. 59)"'5.

Ressalte-se que, o inciso VII-B atinge a proporcionalidade judiciária. O art. $2^{\circ}$ da Lei 8.072/90 é sem duvida o mais polêmico, devido às conseqüências que suas restrições acarreta aos agentes dos delitos nele tipificados, verbis:

"Os crimes hediondos, a prática de tortura, o tráfico ilícito de entorpecentes e drogas afins e o terrorismo são insuscetíveis de: I. anistia, graça e indulto; II. fiança e liberdade provisória. $\$ 1^{\circ}$. A pena por crime previsto neste artigo será cumprida integralmente em regime fechado. $\S 2^{\circ}$. Em caso de sentença condenatória, o juiz decidirá fundamentalmente se o réu poderá apelar em liberdade. $\$ 3^{\circ}$. A prisão temporária, sobre a qual dispõe a Lei $n^{\circ} 7.960$, de 21 de dezembro de 1989, nos crimes previstos neste artigo, terá o prazo de 30 (trinta) dias, prorrogável por igual período em caso de extrema e comprovada necessidade”.

${ }^{4}$ Código Penal Comentado, 6a ed., São Paulo, Renovar, p. 553.

${ }^{5}$ Luiz Régis Prado, Curso de Direito Penal Positivo, $3^{\mathrm{a}}$ ed., vol. 1, Revista dos Tribunais, São Paulo, p. 126. 
O legislador fez uma interpretação ampliativa do inciso XLIII, do art. $5^{\circ}$ da Constituição Federal, que define expressamente somente a proibição dos benefícios da graça, anistia e a fiança, ou seja, não é permitido ao legislador utilizar a interpretação ampliativa para prejudicar o réu sob pena de lesar o princípio da irretroatividade de lei e sua execução “tratase de restringir o arbítrio legislativo e judicial na elaboração ou aplicação retroativa de lei prejudicial" ${ }^{6}$. Novamente, Celso Delmanto comenta o fenômeno:

"A respeito da vedação do indulto, há duas posições na doutrina (cf. Alberto Silva Franco, Crimes hediondos, $3^{a}$ ed., Revista dos Tribunais, pp. 71-4): 1. Não é inconstitucional, pois seria ilógico que a Constituição, em seu art. $5^{\circ}$, XLIII, vedasse a graça (clemência em regra individual e solicitada) e permitisse o indulto (clemência em regra geral e espontânea). Para essa corrente o termo graça, utilizado no art. $5^{\circ}$, XLIII, tem sentido amplo, compreendendo a graça, em sentido estrito, e o indulto. 2. É inconstitucional, não podendo a lei ordinária extrapolar a Magna Carta e restringir atribuição privativa do Presidente da República (art. 83, XII, da CR/88). Entendemos mais acertada a segunda posição, pois os Direitos e Garantias Fundamentais devem ser interpretados 'de maneira a ampliar, em benefício da liberdade, os preceitos de entendimento duvidoso' (Themistocles Cavalcanti, Do Controle da Constitucionalidade, Forense, 1986, p. 164) e não podem ser restringidos "a não ser que a restrição esteja expressamente admitida pela própria constituição” (J.J. Gomes Canotilho e Vital Moreira, Constituição da República Portuguesa Anotada, $3^{a}$ ed., Coimbra, pp. 148-9)"”.

Esta divergência doutrinária foi extinta em relação o crime de tortura que na Lei $n^{\circ} 9.455$, de 7 de abril de 1997 , em seu art. $1^{\circ}$, $\S 6^{\circ}$ dispõe somente sobre a impossibilidade de concessão da graça ou anistia.

${ }^{6}$ Código Penal Comentado, 6 a ed., São Paulo, Renovar, p. 68.

${ }^{7}$ Celso Delmanto, Código Penal Comentado, 6a ed., São Paulo, Renovar, p. 204. 
Em relação à fiança e a liberdade provisória, estas, tiveram sua aplicação vedada nos termos do inciso II, do art. $2^{\circ}$ da Lei dos Crimes Hediondos. E no art. $5^{\circ}$, inciso XLIII da Constituição Federal somente prever a inafiançabilidade, logo assim, o legislador ordinário comete outro deslize interpretando ampliativamente o inciso da Constituição que restringi direitos. Guilherme de Souza Nucci “nessas situações, a Lei 8.072/90 (art. $2^{\circ}$, II) cuidou de vedar, também, a liberdade provisória, sem fiança. Apesar de rigorosa a disposição, ao menos não há contradição, pois não se solta nem com fiança, nem sem o pagamento da fiança” ${ }^{8}$.

A OAB (Ordem dos Advogados do Brasil), em uma proposta votada pelos conselheiros federais, da mesma organização, definiu vários pontos fundamentais para serem alterados, na Lei dos Crimes Hediondos, e um deles é restituir ao juiz autonomia para analisar as peculiaridades de cada caso e decidir se deve ou não manter o criminoso atrás das grades, concedendo através da liberdade provisória o direito do réu responder o processo em liberdade. Somos favoráveis a proposta da OAB porque acreditamos que negada a liberdade provisória que, somente ocorre antes da sentença transitada em julgado, estaremos desrespeitando o princípio da presunção de violência (art. 5², LVII, da CF/88).

\subsection{Impedimento de Progressão de Regime na Lei 8.072/90}

São grandes as críticas, também, ao $\S 1^{\circ}$, art. $2^{\circ}$, pois neste não se aplica progressão de regime aos condenados por crimes hediondos. Nele, o regime adotado é o integralmente fechado "ferindo" diretamente o princípio da individualização da pena, previsto na Constituição Federal como direitos fundamentais individuais no art. 5, XLVI - "a lei regulará a individualização da pena e adotará, entre outras: a) privação ou restrição da liberdade; b) perda de bens; c) multa; d) prestação social alternativa; e) suspensão ou interdição de direitos”.

O parágrafo $1^{\circ}$, art. $2^{\circ}$ da Lei $8.072 / 90$, fere o princípio da individualização da pena (art. $5^{\circ}$, XLVI, CF/88), mas, para tratarmos deste princípio é necessário um breve comentário sobre o princípio da igualdade, que é essencial ao Estado Democrático de Direito.

${ }^{8}$ Guilherme de Souza Nucci, Código de Processo Penal Comentado, $3^{\mathrm{a}}$ ed., Revista dos Tribunais, São Paulo, 2004, p.583. 
A Constituição no art. $5^{\circ}$, caput, estabelece a igualdade como, fundamental ao desenvolvimento de uma sociedade justa, dizendo que “todos são iguais perante a lei, sem distinção de qualquer natureza”. Pois, como diz Cármen Lúcia Antunes Rocha: "Igualdade constitucional é mais que uma expressão de Direito; é um modo justo de se viver em sociedade. Por isso é princípio posto como pilar de sustentação e estrela de direção interpretativa das normas jurídicas que compõem o sistema jurídico fundamental” ${ }^{9}$.

Muito discutido o tema referente à igualdade formal e material, como, aqui, não é o local oportuno para aprofundarmos tal assunto, somente faremos a distinção das duas. A igualdade formal é aquela que a lei deixa todos os indivíduos, nas mesmas condições de acesso aos direitos e garantias fundamentais. Aigualdade material é aquela quando o legislador e o aplicador da lei tratam os desiguais de maneira desigual, com o intuito de aplicar realmente a justiça, a quem tenha direito. Embora, empolgante o assunto, a questão aqui é outra. O parágrafo em analise $\left(\S 1^{\circ}\right.$, art. $\left.2^{\circ}\right)$ fere ou não o princípio da individualização da pena? José Afonso da Silva explica que:

"A realização da igualdade perante a justiça, assim, exige a busca da igualização de condições dos desiguais, o que implica conduzir o juiz a dois imperativos, como observa Ingber: de um lado, cumpre-lhe reconhecer a existência de categorias cada vez mais numerosas e diversificadas, que substituem a idéia de homem, entidade abstrata, pela noção mais precisa de indivíduo caracterizado pelo grupo que se insere de fato; de outro lado, deve ele, apreciar os critérios de relevância que foram adotados pelo legislador. É essa doutrina que orienta o princípio da igualdade da justiça na imposição de pena para o mesmo delito. Seria injusto fosse aplicada a mesma pena sempre em atendimento a uma igualdade abstrata. Aplicando-se matematicamente a mesma pena para o mesmo crime, que, por regra, é praticado em circunstâncias diferentes por pessoas de condições

${ }^{9}$ Curso de Direito Constitucional Positivo,18 ed., Malheiros, São Paulo, 2000, p. 217. 
distintas. Para que tal abstração não ocorra é que, além das circunstâncias atenuantes ou agravantes, se impõe a regra da individualização da pena (art. $\left.5^{\circ}, X L V I\right){ }^{\prime \prime}$.

Mesmo diante de tantos fundamentos plausíveis a alteração da Lei dos Crimes Hediondos, o Supremo Tribunal Federal, em decisões recentes vem mantendo o mesmo entendimento do Superior Tribunal de Justiça que, nos autos do $\mathrm{HC}^{\circ}{ }^{\circ}$ 21.794-0 - SP tendo como relatora a Ministra LAURITA VAZ da Quinta Turma, decidiu unanimemente:

"Encontra-se superada a controvérsia em torno da argüida inconstitucionalidade do art. $2^{\circ}, \S 1^{\circ}$, da Lei 8.702/90, porquanto o Supremo Tribunal Federal temse manifestado reiteradamente, acerca da constitucionalidade daquela, não tendo a Lei 9.455/ 97 derrogado o referido artigo, restando, pois, inviável a progressão de regime prisional nas hipóteses de condenação por crime hediondo".

Não resta dúvida depois da citação de José Afonso da Silva, que o princípio da individualização da pena foi desrespeitado pela Lei dos Crimes Hediondos. A OAB (Ordem do Advogados do Brasil), também, questiona a mudança brevemente, dessa lei, que tantos transtornos tem gerado aos agentes de crimes hediondos. Embora, sejam delinqüentes não podemos deixar de analisar as condições pessoais do agente em cada caso concreto, sob o risco de cometer graves injustiças que na grande maioria das vezes são irreparáveis.

\subsection{Concessão de Livramento Condicional}

A Lei 8.072/90 alterou o art. 83 do Código Penal, incluindo em sua redação o inciso $\mathrm{V}$, que dispõe sobre o Livramento Condicional aos condenados por crimes hediondos, a prática da tortura, o tráfico ilícito de entorpecentes e drogas afins, e o terrorismo. $\mathrm{O}$ apenado que tiver cumprido mais de dois terços da pena, não sendo reincidente específico, em crimes dessa natureza, se concederá o Livramento Condicional.

10 Apud José Afonso da Silva, Curso de Direito Constitucional Positivo,18 ed., Malheiros, São Paulo, 2000, p. 223. 
Livramento Condicional é diferente de Progressão de Regime, aquele permitido e obrigatório (art. 83, V, do CP), desde que, o apenado preencha os requisitos objetivos e subjetivos. Já a progressão não é permitida de forma alguma, pois os crimes hediondos e os a ele equiparados na Lei 8.702/90 são insuscetíveis de progressão do regime integralmente fechado para outro qualquer.

\subsection{O Aumento de Pena do art. $9^{\circ}$ e o Bis in Idem}

$\mathrm{O}$ art. $9^{\circ}$ da Lei dos Crimes Hediondos, prever um aumento de metade na pena, respeitando o limite de 30 (trinta) anos de reclusão, estando a vítima em qualquer uma das hipóteses referidas no art. 224 do Código Penal. Este aumento incide sob os crimes dos arts. 157, § $3^{\circ}, 158, \S 2^{\circ}, 159$, caput e seus $\S \S 1^{\circ}, 2^{\circ}$ e $3^{\circ}, 213$, caput, e sua combinação com o art. 223, caput e parágrafo único, 214 e sua combinação com o art. 223, caput e parágrafo único, todos do Código Penal. Para Celso Delmanto:

“A melhor interpretação é que o aumento de pena, previsto no art. $9^{\circ}$ da LCH, dada a expressa referência ao art. 223, caput e parágrafo único, do CP, somente ocorrerá havendo lesão corporal grave ou morte, sob pena da bis in idem, uma vez que o acusado já está sendo punido em virtude da presunção de violência prevista no art. 224 do CP”.

A favor deste posicionamento o (art. 224) do CP é inconstitucional por desprezar a responsabilidade subjetiva, sendo intolerável a responsabilidade objetiva (STJ, Resp 46.424, DJU 8.8.94. p. 19576, in RBCCr 8/227); no mesmo sentido, o atentado violento ao pudor cometido mediante violência presumida (art. 224, a) não é considerado crime hediondo (TJSP, RT 780/597-8); igualmente o estupro (STJ, HC 13.129/ SP, DJU 19.02.01, p. 247). Contra, o Egrégio Superior Tribunal de Justiça, nos autos do $\mathrm{HC} \mathrm{n}^{\circ}$ 31.614-0 - SP da relatoria do Min. PAULO MEDINA da Sexta Turma, decidiu o julgado, publicado em 17.02.2004: “O estupro e o atentado violento ao pudor ainda que praticados na forma simples, seja com violência real ou presumida, configuram crimes hediondos".

O Pretório Excelso vem atualmente decidindo neste mesmo sentido, com o intuito de por fim a mais uma divergência entre a doutrina e a jurisprudência. 


\section{\ ConCLUSÃo}

No Brasil, a implantação da Lei dos Crimes Hediondos não diminuiu a criminalidade, principal finalidade para a qual foi criada, demonstrando não ser, severas penas, a solução ideal em qualquer sistema.

A OAB elaborou recentemente um projeto arrojado com o objetivo de alterar pontos cruciais da Lei 8.702/90 como, a concessão da progressão de regime e a liberdade provisória impedidos por esta lei.

Em nosso ponto de vista a solução seria unir programas sociais e normas penais justas não tendenciosas ou severas, e sim, normas eficazes impossíveis de gerar no seio da população o espírito da impunidade fundamental a destruição da justiça.

Como será possível discutirmos alterações profundas na aplicação da Lei dos Crimes Hediondos, se nosso sistema penitenciário vital para estas encontrase as "portas" da falência. Este em decadência torna-se impossível falarmos sobre os princípios fundamentais de um Estado Democrático de Direito, por tornarem-se meras abstrações dentro dos estabelecimentos carcerários, aonde o que prevalece é a lei do mais forte (rico), pois, a eles seus direitos são garantidos pela justiça brasileira.

Não seria o momento ideal para pormos em prática os princípios fundamentais de um Estado Democrático de Direito, que visa uma sociedade justa, igualitária, digna e soberana. E não, uma sociedade manipulada pelos detentores do poder político-econômico que através do sensacionalismo fantástico dos meios de comunicação conseguem domar uma população carente de educação, saúde, emprego, moradia e resumindo tudo isto a dignidade humana que hoje é mera fantasia e demagogia dos políticos que temos no "Brasil preparadíssimo para mudanças profundas no ordenamento jurídico”. 


\section{Bibliografia}

PRADO, Luiz Régis. Curso de Direito Penal Positivo. $3^{\mathrm{a}}$ ed., São Paulo. RT, 2002, Vol. 1.

Delmanto, Celso. Código Penal Comentado. 6a ed., São Paulo. Renovar, 2002.

LEAL, João José. Lei dos Crimes Hediondos ou Direito Penal da Severidade. $40^{\mathrm{a}}$ ed., Revista Brasileira de Ciências Criminais, 2002.

SILVA, José Afonso da. Curso de Direito Constitucional Positivo. 18 ed., São Paulo. Malheiros, 2000.

MORAES, Alexandre de. Direito Constitucional. 13 ${ }^{\mathrm{a}}$ ed., São Paulo. Atlas, 2003.

NUCCI, Guilherme de Souza. Código de Processo Penal Comentado. $3^{\mathrm{a}}$ ed., São Paulo. RT, 2004.

ROCHA, Carmem Lúcia Antunes. Curso de Direito Constitucional Positivo. $18^{\mathrm{a}}$ ed., São Paulo: Malheiros, 2000.

Código Penal Comentado. 6a ed., São Paulo: Renovar, 2003. 